\title{
ANALIZA WARTOŚCI OSIADAŃ KONSOLIDOWANYCH GRUNTÓW ORGANICZNYCH MODELEM NUMERYCZNYM W PORÓWNANIU Z WARTOŚCIAMI POMIERZONYMI
}

\begin{abstract}
W pracy została przeprowadzona analiza wartości osiadań konsolidowanych gruntów organicznych modelem numerycznym w porównaniu z wartościami pomierzonymi. Na podstawie przedstawionego modelu do obliczeń wyznaczono osiadania dla nasypu posadowionego na gruncie organicznym. Osiadanie zostało obliczone metodą odkształceń jednoosiowych (metoda normowa) z edometrycznym modułem ściśliwości pierwotnej oraz metodą, która uwzględnia moduł ściśliwości konsolidowanych gruntów organicznych według Meyera. Następnie otrzymane wyniki obu metod porównano z osiadaniami pomierzonymi.
\end{abstract}

Słowa kluczowe: moduł ściśliwości, grunty organiczne, nasyp, model Meyera

\section{Wstęp}

Podczas projektowania obiektów posadowionych na podłożu organicznym bardzo istotnym elementem jest jego osiadanie. Natomiast budowa obiektu na takim podłożu jest jednym z najtrudniejszych zadań inżynierskich. Przyczyną problemu jest charakterystyczna dla gruntów organicznych bardzo duża ściśliwość wynikająca $z$ ich cech fizycznych oraz genezy gruntu $[4,7]$.

$\mathrm{W}$ pracy przeprowadzono analizę wartości osiadań obliczonych z pomierzonymi dla konsolidowanych gruntów organicznych obciążonych nasypem.

\footnotetext{
1 Autor do korespondencji / corresponding author: Ryszard Coufal, Zachodniopomorski Uniwersytet Technologiczny w Szczecinie, Katedra Geotechniki, al. Piastów 50, 70-310 Szczecin; tel. 914494371; coufal@zut.edu.pl

${ }^{2}$ Magdalena Olszewska, Zachodniopomorski Uniwersytet Technologiczny w Szczecinie, Katedra Geotechniki, al. Piastów 50, 70-310 Szczecin; tel.914494515; magdalena.olszewska@ zut.edu.pl
} 


\section{Model matematyczny osiadania nasypu na gruntach organicznych}

W modelu użytym do przeprowadzonych analiz przyjęto, że naprężenia od obciążenia zewnętrznego w warstwie gruntów organicznych są stałe, a warstwa gruntów nośnych zalegająca poniżej gruntów organicznych jest nieodkształcalna. Natomiast przy obliczaniu osiadań założono odkształcenia jednoosiowe pod każdym wydzielonym obszarem obliczeniowym nasypu $[1,2,10,13]$.

Przy założeniu, że rozkład naprężeń w warstwie gruntów organicznych (ze względu na ich właściwości fizyczne i mechaniczne $[5,6,7])$ jest stały, naprężenia można wyznaczyć zgodnie z teorią Boussinesqa z zależności [13]:

$$
\sigma_{z}=\frac{3 P z^{3}}{2 \pi\left(l^{2}+z^{2}\right)^{\frac{5}{2}}}
$$

gdzie: $P$ - siła działająca na podłoże gruntowe w analizowanym obszarze obliczeniowym $[\mathrm{kN}]$,

$z$-głębokość rozpatrywanego miejsca [m],

$l$ - odległość siły od analizowanego miejsca w płaszczyźnie nasypu [m] określona według zależności:

$$
l=\sqrt{\left(x-x_{0}\right)^{2}+\left(y-y_{0}\right)^{2}}
$$

gdzie: $x, y$-współrzędne przyłożenia siły w płaszczyźnie nasypu [m].

Do wyznaczenia naprężeń nasyp należy podzielić na obszary obliczeniowe i wyznaczyć siłę działającą w jego środku. Następnie korzystając z zasady superpozycji wyznaczyć naprężenia $[1,2,13]$.

Do określenia osiadań obiektu budowlanego należy znać moduł ściśliwości gruntów organicznych. Najczęściej określany jest on podczas badania edometrycznego. Moduł ściśliwości gruntów organicznych określany w edometrze może mieć wartość inną niż w rzeczywistości.

Sposób wyznaczenia modułu ściśliwości konsolidowanych gruntów organicznych opisał Meyer [5, 6]. Moduł ten można wyznaczyć zależnością (3):

$$
M\left(\sigma_{0}\right)=M_{0}\left[1+\frac{\kappa-1}{n_{0}} \cdot \frac{\sigma_{0}}{M_{0}}\right]^{\frac{\kappa}{\kappa-1}}
$$

gdzie: $M_{0}$ - edometryczny moduł ściśliwości gruntów organicznych [kPa],

$s$-wartość osiadania nasypu po zakończeniu procesu konsolidacji [m],

$n_{0}$ - porowatość gruntu organicznego przed próbnym obciążeniem [-],

$\kappa$ - parametr bezwymiarowy określany na podstawie badań laboratoryjnych [-]. 
Parametry $\kappa$ i $n_{0}$ gruntów organicznych z okolic Szczecina można wyznaczyć na podstawie związków empirycznych podanych przez Meyera [6]:

$$
\begin{aligned}
& n_{0}=1-\frac{1}{12} \sigma_{k o n}^{1 / 3} \\
& \kappa=2,2 \sigma_{k o n}^{-1 / 18}
\end{aligned}
$$

gdzie: $\sigma_{k o n}$ - naprężenia na powierzchni kontaktowej nasypu z gruntem organicznym $[\mathrm{kPa}]$.

Wyznaczając osiadanie zgodnie w wytycznymi normowymi [11, 12] przyjmuje się stały moduł ściśliwości w wydzielonej warstwie. Jest to głównie edometryczny moduł ściśliwości przyjmowany na podstawie wykonanych badań laboratoryjnych.

Osiadanie oblicza się według zależności (6):

$$
s=\frac{\sigma_{z}}{M_{0}} H_{T}
$$

gdzie: $M_{0}$ - edometryczny moduł ściśliwości pierwotnej [kPa],

$s$-osiadanie nasypu [m],

$\sigma_{z}$ - naprężenia od obciążenia zewnętrznego [kPa],

$H_{T}$ - miążzzość gruntów organicznych przed konsolidacją [m].

Obliczając osiadanie podejściem normowym $[11,12]$ wyznaczymy stałą wartość osiadania dla nasypu. Nasyp jednak nie osiada równomiernie. Największe osiadania wystąpią w środku nasypu, czyli tam gdzie będą największe naprężenia od obciążenia zewnętrznego. Na rysunku 1. pokazano schemat rzeczywistego osiadania.

Nierównomierne osiadanie nasypu wynika m. in. z braku jego sztywności, jak również zmiennej wartości modułu ściśliwości konsolidowanych gruntów organicznych w planie nasypu $[1,2,3,8,9]$.

Osiadanie, w którym uwzględnimy uzmiennioną wartość modułu ściśliwości konsolidowanych gruntów organicznych według Meyera [5, 6] w planie nasypu można zapisać:

$$
s_{i}=\frac{\sigma_{z i}}{M_{0}\left[1+\frac{\kappa-1}{n_{0}} \cdot \frac{\sigma_{0}}{M_{0}}\right]^{\frac{\kappa}{\kappa-1}}} H_{T}
$$

gdzie: $s_{i}$ - osiadanie analizowanego obszaru obliczeniowego [m],

$\sigma_{z i}$ - naprężenia od obciążenia zewnętrznego $\mathrm{w}$ analizowanym obszarze obliczeniowym [kPa]. 


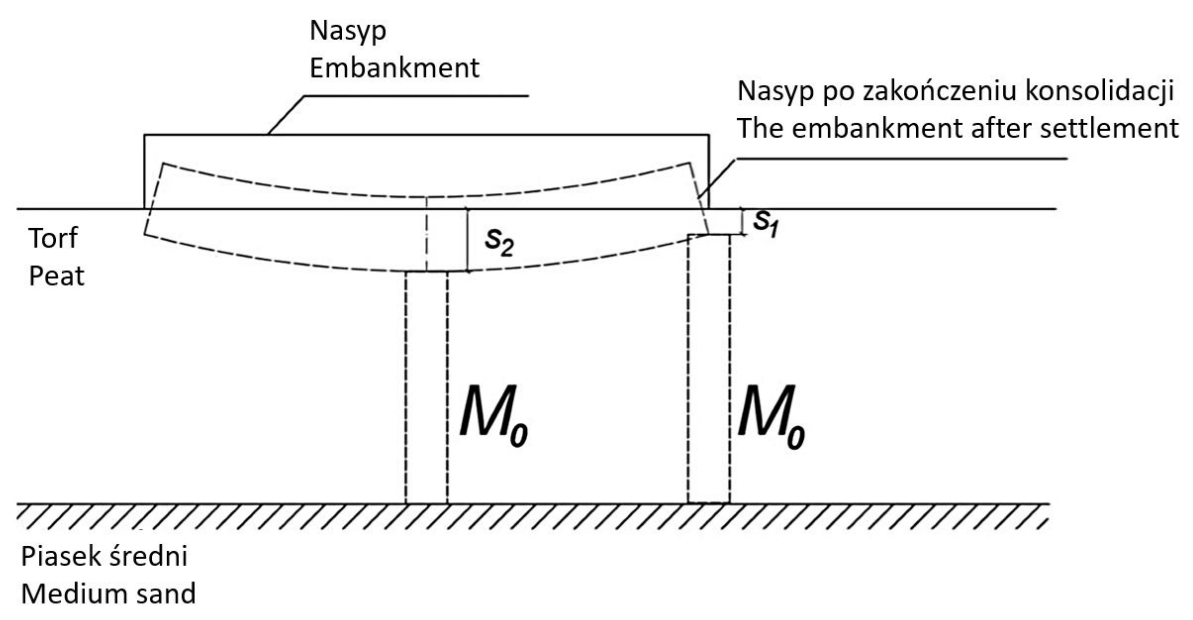

Rys. 1. Schemat rzeczywistego osiadania nasypu. Oznaczenia: $M_{0}$-edometryczny moduł ściśliwości gruntu organicznego, $s_{1}$ - osiadanie na brzegu nasypu; $s_{2}$ - osiadanie w środku nasypu

Fig. 1. Scheme of the actual settlement of the embankment. Notations: $M_{0}$ - oedometric modulus of compressibility, $s_{1}$ - settlement at the edge of the embankment; $s_{2}-$ settlement in the middle of the embankment

Osiadanie w tym przypadku wyznacza się dla każdego wydzielonego obszaru obliczeniowego nasypu.

\section{Analiza osiadań konsolidowanych gruntów organicznych}

$\mathrm{Na}$ podstawie opisanego modelu matematycznego obliczono osiadania zgodnie z podejściem normowym oraz osiadania uwzględniające zmienny moduł ściśliwości konsolidowanych gruntów organicznych. Następnie obliczone osiadania porównano z osiadaniami określonymi w terenie.

Przeanalizowano osiadanie nasypu znajdującego się w Szczecinie. Nasyp o wysokości $2 \mathrm{~m}$ i wymiarach 63,58 $\mathrm{m}$ na 64,76 m wykonano z piasku średniego średnio zagęszczonego, o ciężarze objętościowym $17,5 \mathrm{kN} \cdot \mathrm{m}^{-3}$. Posadowiony został na 9 metrowej warstwie torfu o edometrycznym module ściśliwości $M_{0}=320 \mathrm{kPa}[2,3,6]$. Nasyp wywiera obciążenie $35 \mathrm{kPa}$ warstwę gruntów organicznych.

W celu przeprowadzenia obliczeń nasyp podzielono na 64 obszary obliczeniowe. Schemat nasypu pokazano na rysunku 2.

Następnie w miejscach reperów obliczono naprężenia od obciążenia nasypem zgodnie z teorią Boussinesqa uwzględniając wpływ każdego wydzielonego pola. Wyznaczony rozkład naprężeń pokazano na rysunku 3. 


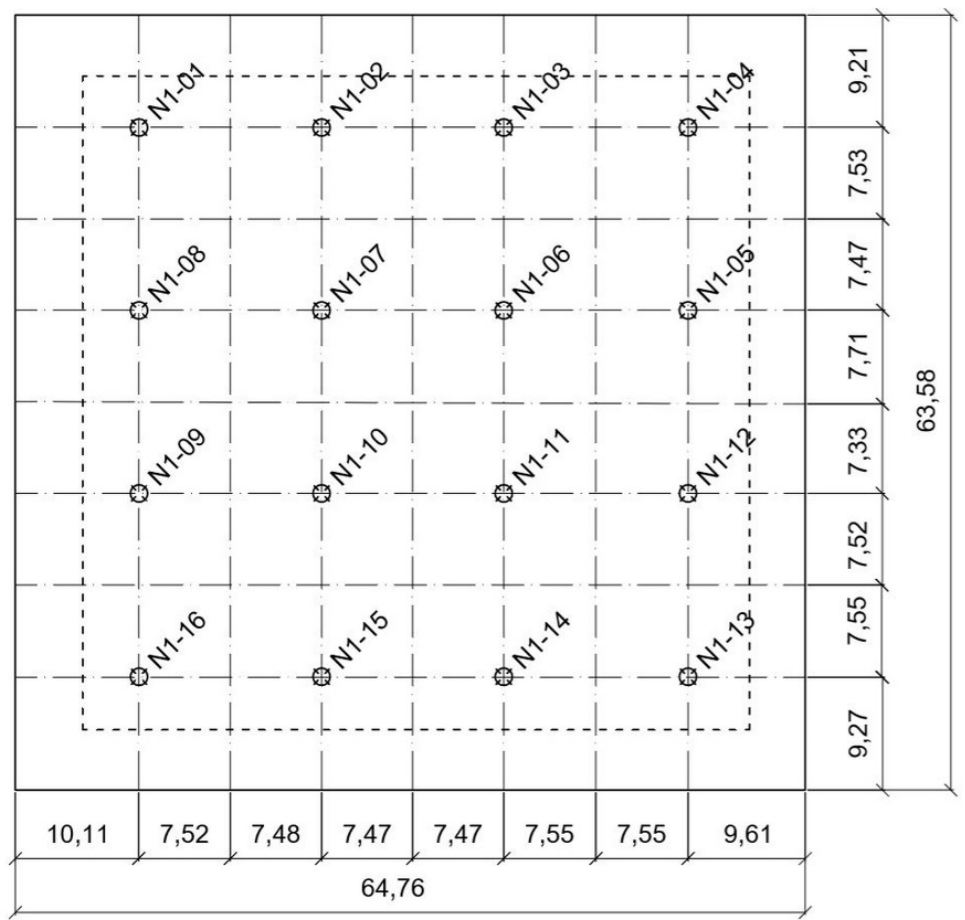

Rys. 2. Schemat nasypu wraz z numeracją reperów i podziałem na obszary obliczeniowe

Fig. 2. Scheme of the embankment with top view of the numbering of benchmarks and division of the embankment into calculation plots

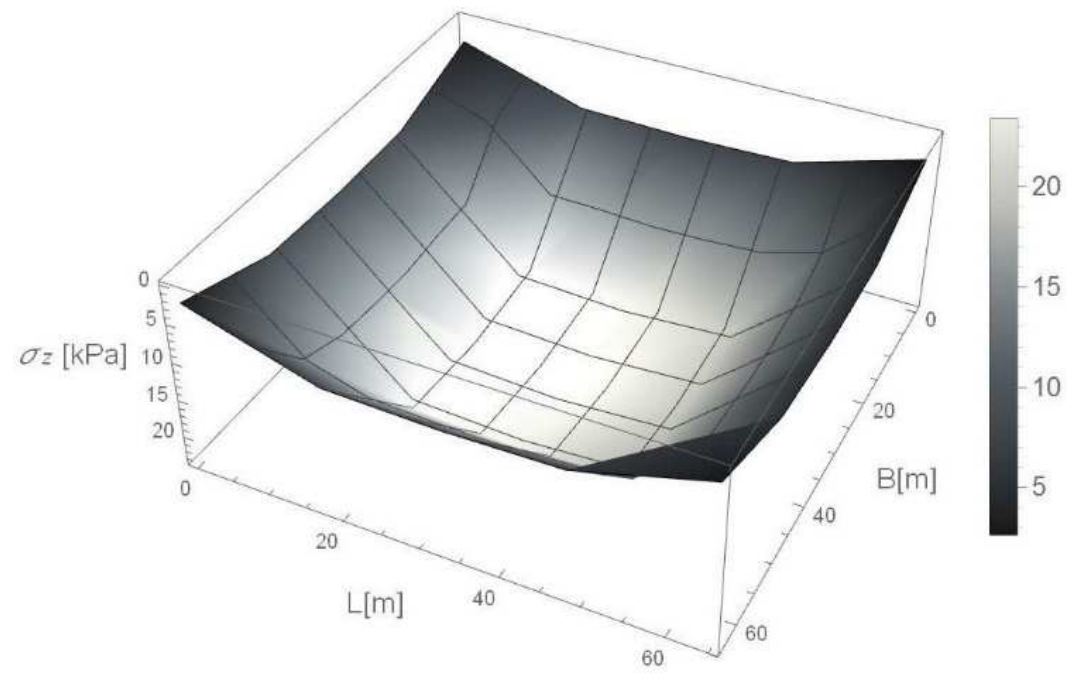

Rys. 3. Rozkład naprężeń pod nasypem

Fig. 3. Stress distribution under the embankment 
Obliczono wartości modułu ściśliwości konsolidowanych gruntów organicznych na podstawie modelu Meyera $[6,7] \mathrm{w}$ miejscach analizowanych osiadań. Wyniki przedstawiono w tabeli 1.

Tabela 1. Wartości modułów ściśliwości konsolidowanych gruntów organicznych

Table 1. Values of modulus of compressibility of consolidated organic soils

\begin{tabular}{|c|c|c|c|c|c|c|c|c|}
\hline $\begin{array}{c}\text { Nr reperu } \\
\text { Number of } \\
\text { benchmark }\end{array}$ & N1-01 & N1-02 & N1-03 & N1-04 & N1-05 & N1-06 & N1-07 & N1-08 \\
\hline $\boldsymbol{M}\left(\boldsymbol{\sigma}_{\boldsymbol{z}}\right)[\mathbf{k P a}]$ & 377,69 & 396,91 & 396,89 & 377,19 & 380,21 & 410,98 & 411,03 & 381,80 \\
\hline $\begin{array}{c}\text { Nr reperu } \\
\text { Number of } \\
\text { benchmark }\end{array}$ & N1-09 & N1-10 & N1-11 & N1-12 & N1-13 & N1-14 & N1-15 & N1-16 \\
\hline $\boldsymbol{M}\left(\boldsymbol{\sigma}_{z}\right)[\mathbf{k P a}]$ & 381,80 & 411,04 & 410,99 & 380,22 & 377,37 & 397,07 & 398,97 & 377,83 \\
\hline
\end{tabular}

Wyznaczone moduły ściśliwości są większe od 6,52 do 19,69\% od edometrycznego modułu ściśliwości, co szerzej opisano w [3].

Wykonano obliczenia osiadania. Pierwsze obliczenia wykonano podejściem normowym. Znając edometryczny moduł ściśliwości warstwy torfu oraz naprężenia od obciążenia zewnętrznego obliczono osiadanie. Wyniki przedstawiono w tabeli 2 .

Tabela 2. Obliczone osiadanie według podejścia normowego

Table 2. Determined values of settlement according to the standard approach

\begin{tabular}{|c|c|c|c|c|c|c|c|c|}
\hline $\begin{array}{c}\text { Nr reperu } \\
\text { Number of } \\
\text { benchmark }\end{array}$ & N1-01 & N1-02 & N1-03 & N1-04 & N1-05 & N1-06 & N1-07 & N1-08 \\
\hline $\boldsymbol{s}[\mathbf{m}]$ & 0,606 & 0,796 & 0,796 & 0,601 & 0,631 & 0,931 & 0,932 & 0,647 \\
\hline $\begin{array}{c}\text { Nr reperu } \\
\text { Number of } \\
\text { benchmark }\end{array}$ & N1-09 & N1-10 & N1-11 & N1-12 & N1-13 & N1-14 & N1-15 & N1-16 \\
\hline $\boldsymbol{s}[\mathbf{m}]$ & 0,647 & 0,932 & 0,931 & 0,631 & 0,603 & 0,797 & 0,816 & 0,608 \\
\hline
\end{tabular}

Wyznaczono osiadania nasypu $\mathrm{w}$ oparciu o moduł ściśliwości konsolidowanych gruntów organicznych na podstawie modelu Meyera. Wyniki przedstawiono w tabeli 3 .

Tabela 3. Obliczone osiadanie z uwzględnieniem wartość modułu ściśliwości konsolidowanych gruntów organicznych według Meyera

Table 3. Determined values of settlement when the values of modulus of compressibility of organic soils according to Meyer approach is taking into account.

\begin{tabular}{|c|c|c|c|c|c|c|c|c|}
\hline $\begin{array}{c}\text { Nr reperu } \\
\text { Number of } \\
\text { benchmark }\end{array}$ & N1-01 & N1-02 & N1-03 & N1-04 & N1-05 & N1-06 & N1-07 & N1-08 \\
\hline $\boldsymbol{s}[\mathbf{m}]$ & 0,514 & 0,642 & 0,641 & 0,510 & 0,531 & 0,725 & 0,725 & 0,542 \\
\hline $\begin{array}{c}\text { Nr reperu } \\
\text { Number of } \\
\text { bechmark }\end{array}$ & N1-09 & N1-10 & N1-11 & N1-12 & N1-13 & N1-14 & N1-15 & N1-16 \\
\hline $\boldsymbol{s}[\mathbf{m}]$ & 0,542 & 0,725 & 0,725 & 0,531 & 0,511 & 0,643 & 0,654 & 0,515 \\
\hline
\end{tabular}


Można zauważyć, że osiadania obliczone $\mathrm{z}$ uwzględnieniem wartość modułu ściśliwości konsolidowanych gruntów organicznych według Meyera wynoszą średnio $82 \%$ wartości obliczonych podejściem normowym.

Obliczone osiadania porównano z osiadaniami pomierzonymi tego nasypu, którego wielkości przedstawiono w tabeli 4.

Tabela 4. Osiadanie końcowe nasypu

Table 4. Final settlement of the embankment

\begin{tabular}{|c|c|c|c|c|c|c|c|c|}
\hline $\begin{array}{c}\text { Nr reperu } \\
\text { Number of } \\
\text { benchmark }\end{array}$ & N1-01 & N1-02 & N1-03 & N1-04 & N1-05 & N1-06 & N1-07 & N1-08 \\
\hline $\boldsymbol{s}[\mathbf{m}]$ & 0,513 & 0,421 & 0,327 & 0,307 & 0,461 & 0,371 & 0,408 & 0,626 \\
\hline $\begin{array}{c}\text { Nr reperu } \\
\text { Number of } \\
\text { benchmark }\end{array}$ & N1-09 & N1-10 & N1-11 & N1-12 & N1-13 & N1-14 & N1-15 & N1-16 \\
\hline $\boldsymbol{s}[\mathbf{m}]$ & 0,247 & 1,175 & 1,12 & 0,261 & 0,102 & 0,472 & 0,457 & 0,179 \\
\hline
\end{tabular}

$\mathrm{Na}$ rysunku 4. przedstawiono porównanie osiadania obliczeniowego wraz z osiadaniem pomierzonym dla poszczególnych reperów. Na wykresie przedstawiono również stosunek osiadania obliczeniowego do osiadania pomierzonego w zależności od metody obliczeń (rys. 5.).

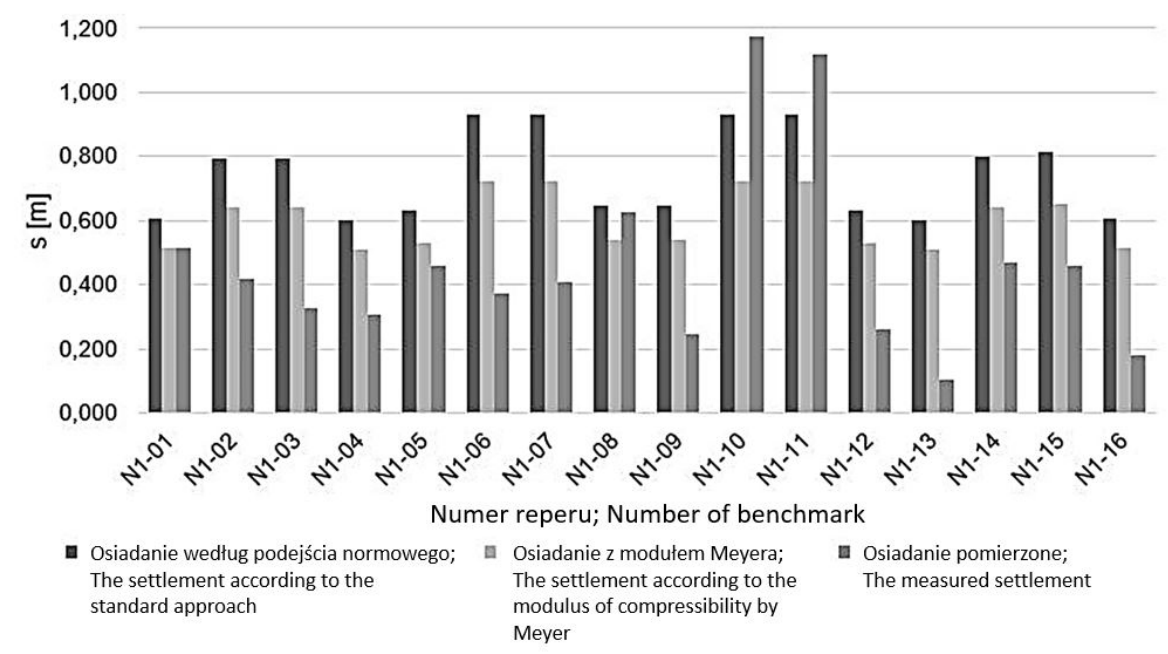

Rys. 4. Porównanie osiadania obliczeniowego z osiadaniem pomierzonym dla poszczególnych reperów

Fig. 4. Comparison of calculation settlement with actual settlement for each benchmarks 


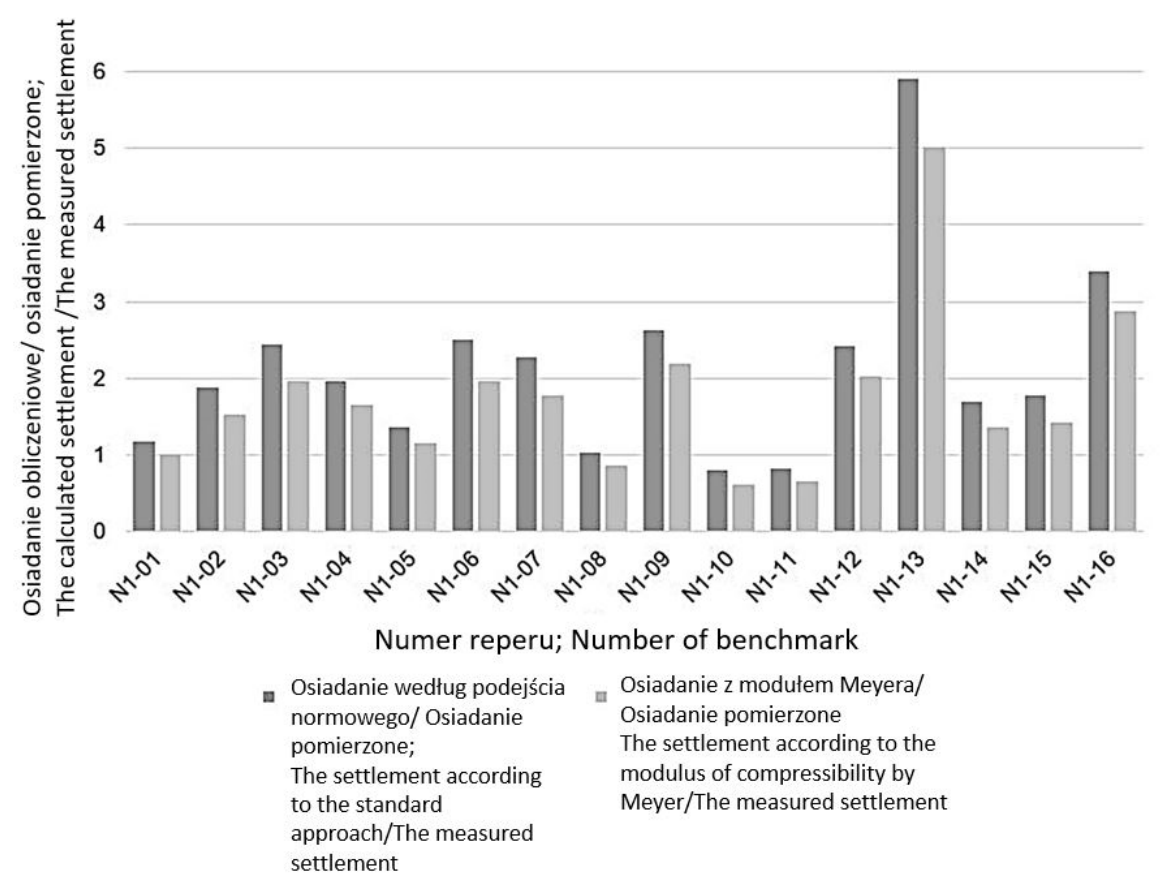

Rys. 5. Stosunek osiadania obliczeniowego do osiadania pomierzonego w zależności od metody obliczeń

Fig. 5. Calculated settlement to measured settlement depending on the calculation method

Można zauważyć, że w głównej mierze osiadanie obliczone obiema metodami jest większe niż osiadanie pomierzone. Średnio osiadanie obliczone metodą normową jest 2,13 razy większe od pomierzonego, natomiast osiadanie obliczone z uwzględnieniem wartość modułu ściśliwości konsolidowanych gruntów organicznych według Meyera jest 1,75 razy większa. $Z$ tego wynika, że bliższe pomierzonym jest osiadanie wyznaczone na podstawie uzmiennionego modułu ściśliwości konsolidowanych gruntów organicznych według Meyera. W efekcie czego wykorzystując zagadnienie odwrotne można posłużyć się zależnością Meyera do wyznaczenia modułu ściśliwości gruntów organicznych w terenie na podstawie znanych wartości osiadania nasypu przeciążającego ten rodzaj podłoża.

Należy zwrócić uwagę na zależność osiadania obliczonego obiema metodami do pomierzonego w miejscach reperów N1-09, N1-10 oraz N1-13, które odbiegają od pozostałych wartości. W miejscach reperów N1-09, N1-10 osiadanie obliczeniowe jest mniejsze niż pomierzone, natomiast $\mathrm{w}$ miejscu N-1-13 osiadanie obliczeniowe jest około 5,46 razy większe niż pomierzone. Wynikać to może z lokalnej zmienności miąższości konsolidowanych gruntów organicznych w porównaniu do wartości przyjętej w obliczeniach, bądź innej lokalnej wielkości edometrycznego modułu ściśliwości w stosunku do jego wartości przyjętej do obliczeń dla całej warstwy. 


\section{Podsumowanie}

W artykule przeprowadzono analizę wartości osiadań konsolidowanych gruntów organicznych modelem numerycznym $\mathrm{w}$ porównaniu $\mathrm{z}$ wartościami pomierzonymi.

Osiadania obliczeniowe podejściem normowym oraz $\mathrm{z}$ uwzględnieniem wartość modułu ściśliwości konsolidowanych gruntów organicznych według Meyera różnią się od siebie. Obliczenia osiadania na podstawie norm są większe, a osiadania z uwzględnieniem wartości modułu ściśliwości konsolidowanych gruntów organicznych według Meyera stanowią średnio 82\% ich wartości.

Osiadanie obliczeniowe zarówno metodą normową, jak i metodą uwzględniającą moduł ściśliwości konsolidowanych gruntów organicznych według Meyera są osiadaniami większymi niż w pomierzone. Osiadanie obliczone pierwszą metodą jest 2,13 razy większe niż w pomierzone, a drugą 1,75 . $\mathrm{Z}$ przeprowadzonych analiz wynika, że osiadanie $\mathrm{z}$ uwzględnieniem wartości modułu ściśliwości konsolidowanych gruntów organicznych według Meyera jest bliższe wartości pomierzonej.

Dodatkowo na podstawie przeprowadzonej analizy, korzystając z zagadnienia odwrotnego, można wyznaczyć moduły ściśliwości gruntów organicznych $\mathrm{w}$ terenie posługując się zależnością na osiadanie z uwzględnieniem modułu ściśliwości konsolidowanych gruntów organicznych według Meyera.

\section{Literatura}

[1] Coufal R., Olszewska M.: Numeryczne symulacje zmiany wartości modułu ściśliwości gruntu organicznego pod nasypem przeciążającym, Materiały Budowlane, nr 8/2016, 2016, s. 103-105.

[2] Coufal R., Olszewska M.: Przeciążenie gruntu organicznego nasypem pod składowisko przeznaczone do magazynowania elementów konstrukcyjnych, Acta Sci. Pol. Architectura, 15 (3), 2016, s. 93-102.

[3] Coufal R., Olszewska M.: Analiza parametrów konsolidowanego podłoża nasypem z gruntu rodzimego na Ostrowie Grabowskim w Szczecinie, Inżynieria i Budownictwo, 5/2017, 2017,s. 260-262.

[4] Lechowicz Z., Szymański A., Odkształcenia i stateczność nasypów na gruntach organicznych, część II, Metodyka Obliczeń, Wydawnictwo SGGW, Warszawa, 2002.

[5] Meyer Z.: Empirical model of peat consolidation, Advances in Understanding and Modelling the Mechanical Behaviour of Peat, A.A. Balkema - Rotterdam Brookfield, Delft, 1994, s. 77-82.

[6] Meyer Z.: Czy możemy posadowić obiekty bezpośrednio na torfach?, XXI Seminarium Naukowe z cyklu „Regionalne problemy inżynierii środowiska”, Szczecin, 2014, s. 131-143.

[7] Myślińska E., Grunty organiczne i laboratoryjne metody ich badania, Wydawnictwo Naukowe PWN, Warszawa (2001). 
[8] Olszewska M.: Koncepcja określania modułu ściśliwości gruntów organicznych na podstawie badania osiadań nasypu przeciążającego na poletku doświadczalnym, XXII Seminarium Naukowe z cyklu „Regionalne problemy inżynierii środowiska”, Szczecin, 2015, s. 93-100.

[9] Olszewska M., Model określania parametrów ściśliwości konsolidowanych gruntów organicznych w oparciu o badania in situ, Monografie 2016 (23): Nauki techniczne i inżynieryjne, cześć III: Badania i rozwój młodych naukowców w Polsce, Poznań, 2016, s. 82-89.

[10] Szczygielski T.: Analiza warunków konsolidacji torfów przeciążonych warstwą popiołów, Rozprawa doktorska. Politechnika Szczecińska. Wydział Budownictwa i Architektury, Szczecin, 2008, s.73-76.

[11] PN-EN 1997-1. Eurokod 7: Projektowanie geotechniczne - Część 1: Zasady ogólne.

[12] PN-B-03020:1981. Grunty budowlane - Posadowienie bezpośrednie budowli Obliczenia statyczne i projektowanie.

[13] Wiłun Z.: Zarys geotechniki, Wydawnictwo WKŁ, Warszawa, 2013.

\title{
ANALYSIS OF SETTLEMENT OF ORGANIC SOIL CALCULATED ACCORDING TO NUMERICAL MODEL IN COMPARISON WITH MEASURED VALUES
}

\begin{abstract}
S u m m a r y
The article analyzes the value of settlement of organic soil by numerical model compared with measured values. On the basic of presented numerical model settlement values were determined for an embankment built on the ground of organic soil. Settlement was calculated by means of simple classical one-dimensional method with an oedometric modulus of compressibility and a method that takes into account the modulus of compressibility of the consolidated organic soil according to Meyer. The obtained results of both methods were then compared with the actual settlement of the embankment.
\end{abstract}

Przestano do redakcji: $19.06 .2017 \mathrm{r}$.

Przyjęto do druku: 01.09.2017 r. 